\title{
Genetic diversity analysis in Tunisian perennial ryegrass germplasm as estimated by RAPD, ISSR, and morpho-agronomical markers
}

S. Ghariani ${ }^{1}$, H. Elazreg ${ }^{1}$, N. Chtourou-Ghorbel ${ }^{1}$, M. Chakroun $^{2}$ and N. Trifi-Farah ${ }^{1}$

${ }^{1}$ Université Tunis El Manar, Faculté des Sciences de Tunis, Laboratoire de Génétique Moléculaire, Immunologie et Biotechnologie, Campus Universitaire El Manar, Tunisie

'Laboratoire des Productions Animales et Fourragères,

Institut National de Recherche Agronomique de la Tunisie, Ariana, Tunisie

Corresponding author: N. Trifi-Farah

E-mail: neilatrifi@gmail.com

Genet. Mol. Res. 14 (4): 18523-18533 (2015)

Received August 3, 2015

Accepted October 6, 2015

Published December 23, 2015

DOI http://dx.doi.org/10.4238/2015.December.23.40

\begin{abstract}
Tunisia is rich in diverse forage and pasture species including perennial ryegrass. In order to enhance forage production and improve agronomic performance of this local germplasm, a molecular analysis was undertaken. Random amplified polymorphic DNA (RAPD), inter simple sequence repeats (ISSR) and morpho-agronomical traits markers were used for genetic diversity estimation of ryegrass germplasm after screening 20 spontaneous accessions, including a local and an introduced cultivars. Same mean polymorphism information content values were obtained $(0.37)$ for RAPD and ISSR suggesting that both marker systems were equally effective in determining polymorphisms. The average pairwise genetic distance values were 0.57 (morpho-agronomical traits), 0.68 (RAPD), and 0.51 (ISSR) markers data sets. A higher Shannon diversity index was obtained with ISSR marker (0.57) than for RAPD (0.54) and morphoagronomical traits (0.36). The Mantel test based on genetic distances of a combination of molecular markers and morpho-agronomical data exhibited
\end{abstract}


a significant correlation between RAPD and ISSR data, suggesting that the use of a combination of molecular techniques was a highly efficient method of estimating genetic variability levels among Tunisian ryegrass germplasm. In summary, results showed that combining molecular and morpho-agronomical markers is an efficient way in assessing the genetic variability among Tunisian ryegrass genotypes. In addition, the combined analysis provided an exhaustive coverage for the analyzed diversity and helped us to identify suitable accessions showed by Beja and Jendouba localities, which present large similarities with cultivated forms and can be exploited for designing breeding programmes, conservation of germplasm and management of ryegrass genetic resources.

Key words: Genetic diversity; Germplasm; ISSR; Morpho-agronomy; Perennial ryegrass; RAPD

\section{INTRODUCTION}

Perennial ryegrass (Lolium perenne L.) is a diploid species $(2 n=14)$, widespread forage grass in the Mediterranean region. It grows rapidly, is easily established, and often used for stabilization of soils. Lolium perenne is one of the most important cool season perennial grass species in humid and sub-humid areas (Cunningham et al., 1997). Perennial ryegrass is widely planted for range, pasture, hay, and turf. This pasture grass is seeded in mixtures with other, slower-growing, more long-lasting species to provide a quick cover.

Tunisian natural flora is rich in diverse forage and pasture species including perennial ryegrass (Cunningham et al., 1997). In northern Tunisia, evaluation and characterization of ryegrass has become a high-priority task to ensure pasture sustainability. Currently, overgrazing, irregular rainfall, and neglected forage exploitation seriously threaten the local germplasm by severe genetic erosion (Ghariani et al., 2003b). Conservation management of the relatively high number of existing ecotypes with different synonyms and variable commercial values requires the knowledge of genetic diversity within and among local populations, when aiming to develop breeding programs and to conserve these important agronomic resources. Moreover, the genetic relatedness between wild and introduced cultivars that have limited adaptation, persistence, and drought tolerance to the local environment, should be submitted to reliable conservation and selection programs (Cunningham et al., 1997).

In order to enhance forage production and improve agronomic performance of spontaneous autochthonous populations and poor adapted foreign cultivars to Tunisian conditions, the elaboration of a research program is imperative to contribute to the conservation of these germplasms and to promote pasture sustainability.

Recent investigations were undertaken reporting either morphological and/or agronomical traits to identify Tunisian perennial ryegrass accessions (Ghariani et al., 2003a; Ghariani et al., 2003c). Moreover, molecular markers such as restriction fragment length polymorphism (RFLP), random amplified polymorphic DNA (RAPD) (Hayward et al., 1994; Hayward et al., 1998), amplified fragment length polymorphism (AFLP) (Bert et al., 1999), and simple sequence repeat (SSR) markers (Jones et al., 2001; Jones et al., 2002) were used to examine population genetic structure and diversity, and cultivar identification. They were also used to correlate molecular findings with morpho-agronomical traits (Geleta et al., 2006).

Analysis of Tunisian local germplasm was performed using Inter Simple Sequence Repeat 
PCR (ISSR-PCR) (Gupta et al., 1994) and RAPD, detecting the polymorphism level without any previous knowledge of the crop's DNA sequence. These technologies were successfully used for DNA-fingerprinting of a wide range of crop species and to discriminate between closely related genotypes (Fang and Roose, 1997; Gilbert et al., 1999; Ghariani et al., 2003b; Yao et al., 2008). In some cases, molecular data were compared and integrated with phenotypic data to evaluate their utility as a tool for germplasm conservation and plant breeding (Russell et al., 2000; Muthusamy et al., 2008; Krichen et al., 2010; Linos et al., 2014).

The salient features of this work were (i) a comparative analysis using both RAPD and ISSR markers, (ii) the evaluation of the genetic relatedness among molecular and morpho-agronomical markers and (iii) the assessment of genetic diversity between Tunisian spontaneous species and introduced germplasm ryegrass cultivars.

\section{MATERIAL AND METHODS}

\section{Plant material}

Eighteen spontaneous populations, one local and two cultivars were sampled for this study. The spontaneous accessions were collected from the north and northwest of Tunisia and belonged to four different localities (Chakroun et al., 1995), whereas 'Aîn Melliti' (a local cultivar) and 'Talbot' (an introduced cultivar from the Netherlands) were also included. More details about the geographic origin are listed in Table 1. Plant material consisted of young leaves randomly sampled from adult plants and frozen in liquid nitrogen until their use.

\section{Table 1. Lolium perenne L. studied accessions.}

\begin{tabular}{lll}
\hline Locality & Accessions & Abbreviations \\
\hline Nabeul & Menzel Temime & Mt \\
& Sk & Sd \\
Bizerte & Skalba & Bz \\
& Sedjenene & Sn \\
Beja & Bizerte & Tb \\
& Sidi Nsir & Am \\
& Teboursouk & Ad \\
& Ain Melliti & Nf \\
& Amdoun & B1 \\
& Nefza & B2 \\
Jendouba & Beja 1 & B3 \\
& Beja 2 & Hb \\
& Beja 3 & Ta \\
& Hammem Bourguiba & Gh \\
Beja & Tabarka & Ef \\
The Netherlands & Ghardimaou & Dr \\
\end{tabular}

\section{DNA isolation}

DNA was extracted from $1 \mathrm{~g}$ plant material according to a previously described procedure (Dellaporta et al., 1983) with minor modifications adapted to mini extraction (Ghariani et al., 
2003b). The DNA was spectrophotometrically quantified and its integrity was verified by analytic electrophoresis (Sambrook et al., 1989).

\section{RAPD markers}

Eight random decamer primers (Operon Technologies, California, USA) were used for the polymorphism survey. These primers belong to the following sets of useful items OPA, OPB, OPD and OPE (Table 2). The amplifications were carried out according to Trifi et al. (2000). Consistent amplified products were recorded for each primer. Each RAPD marker was assumed to presence (1) or absence (0) of band in order to form a binary data matrix.

\begin{tabular}{|c|c|c|c|c|c|c|}
\hline \multirow[t]{3}{*}{ OP } & \multirow[t]{3}{*}{ Primer Sequence $\left(5^{\prime}-3^{\prime}\right)$} & \multicolumn{2}{|c|}{$\operatorname{Tm}\left({ }^{\circ} \mathrm{C}\right)$} & \multicolumn{3}{|c|}{ Amplified DNA bands } \\
\hline & & \multirow[t]{2}{*}{ Theoretical } & \multirow[t]{2}{*}{ Optimal } & \multirow[t]{2}{*}{ Total } & \multicolumn{2}{|c|}{ Polymorphic } \\
\hline & & & & & Number & $\%$ \\
\hline A-14 & TCTGTGCTGG & 32 & 35 & 8 & 8 & 100 \\
\hline A-20 & GTTGCGATCC & 32 & 35 & 15 & 15 & 100 \\
\hline B-01 & GTTTCGCTCC & 32 & 35 & 13 & 12 & 92.3 \\
\hline B-12 & CCTTGACGCA & 32 & 35 & 12 & 12 & 100 \\
\hline D-12 & CACCGTATCC & 32 & 35 & 9 & 9 & 100 \\
\hline $\mathrm{D}-17$ & TTTCCCACGG & 32 & 35 & 11 & 10 & 91.0 \\
\hline$E-10$ & CACCAGGTGA & 32 & 35 & 12 & 12 & 100 \\
\hline E-16 & GGTGACTGTG & 32 & 35 & 10 & 10 & 100 \\
\hline Total & & & & 90 & 88 & 97.8 \\
\hline Average/primer & & & & 11.25 & 11.0 & 97.8 \\
\hline
\end{tabular}

\section{ISSR markers}

Ten oligonucleotides complementary to the repeated motifs (Microsatellites) were used to successfully screen the ISSR. These primers consist of five 3'-anchored and three unanchored primers arbitrarily chosen. Primer sequences and characteristics are listed in Table 3. PCR amplifications were carried out as previously reported (Ghariani et al., 2003b). Amplified products were compiled into a binary data matrix on the basis of the presence (1) or absence (0) of each band class selected.

\begin{tabular}{|c|c|c|c|c|c|c|}
\hline \multirow[t]{3}{*}{ Primer sequence } & \multicolumn{2}{|c|}{$\operatorname{Tm}\left({ }^{\circ} \mathrm{C}\right)$} & \multirow[t]{3}{*}{$\%$ of GC } & \multicolumn{3}{|c|}{ Amplified DNA bands } \\
\hline & \multirow[t]{2}{*}{ Theoretical } & \multirow[t]{2}{*}{ Optimal } & & \multirow[t]{2}{*}{ Total } & \multicolumn{2}{|c|}{ Polymorphic } \\
\hline & & & & & Number & $\%$ \\
\hline$(\mathrm{TC})_{10} \mathrm{G}$ & 64 & 60 & 52.38 & 13 & 13 & 100 \\
\hline$(\mathrm{TC})_{10} \mathrm{C}$ & 64 & 60 & 52.38 & 15 & 15 & 100 \\
\hline$(\mathrm{GA})_{10} \mathrm{~A}$ & 62 & 57 & 47.62 & 08 & 08 & 100 \\
\hline$(\mathrm{GA})_{10} \mathrm{C}$ & 64 & 60 & 52.38 & 17 & 16 & 94.12 \\
\hline$(\mathrm{GA})_{10}^{10} \mathrm{~T}$ & 62 & 57 & 47.62 & 14 & 12 & 85.71 \\
\hline Total & & & & 67 & 64 & 95.52 \\
\hline Average/3'-Anchored ISSR primer & & & & 13.4 & 12.8 & 95.52 \\
\hline$(A G)_{10}$ & 60 & 55 & 50.00 & 18 & 15 & 83.33 \\
\hline$(\mathrm{CT})_{10}$ & 60 & 55 & 50.00 & 12 & 12 & 100 \\
\hline$(\mathrm{TCC})_{5}$ & 50 & 46 & 66.66 & 10 & 10 & 100 \\
\hline Total & & & & 40 & 37 & 92.50 \\
\hline Average/non-anchored ISSR primer & & & & 13.33 & 12.33 & 92.50 \\
\hline Total & & & & 107 & 101 & 94.39 \\
\hline Average/primer & & & & 13.37 & 12.62 & 94.39 \\
\hline
\end{tabular}




\section{Morpho-agronomical parameters}

All accessions were planted in a randomized complete bloc design with three replications. A total of 17 quantitative and 4 qualitative morpho-agronomical traits were recorded according to previously reported method (Ghariani et al., 2003a; Ghariani et al., 2003c) (Table 4).

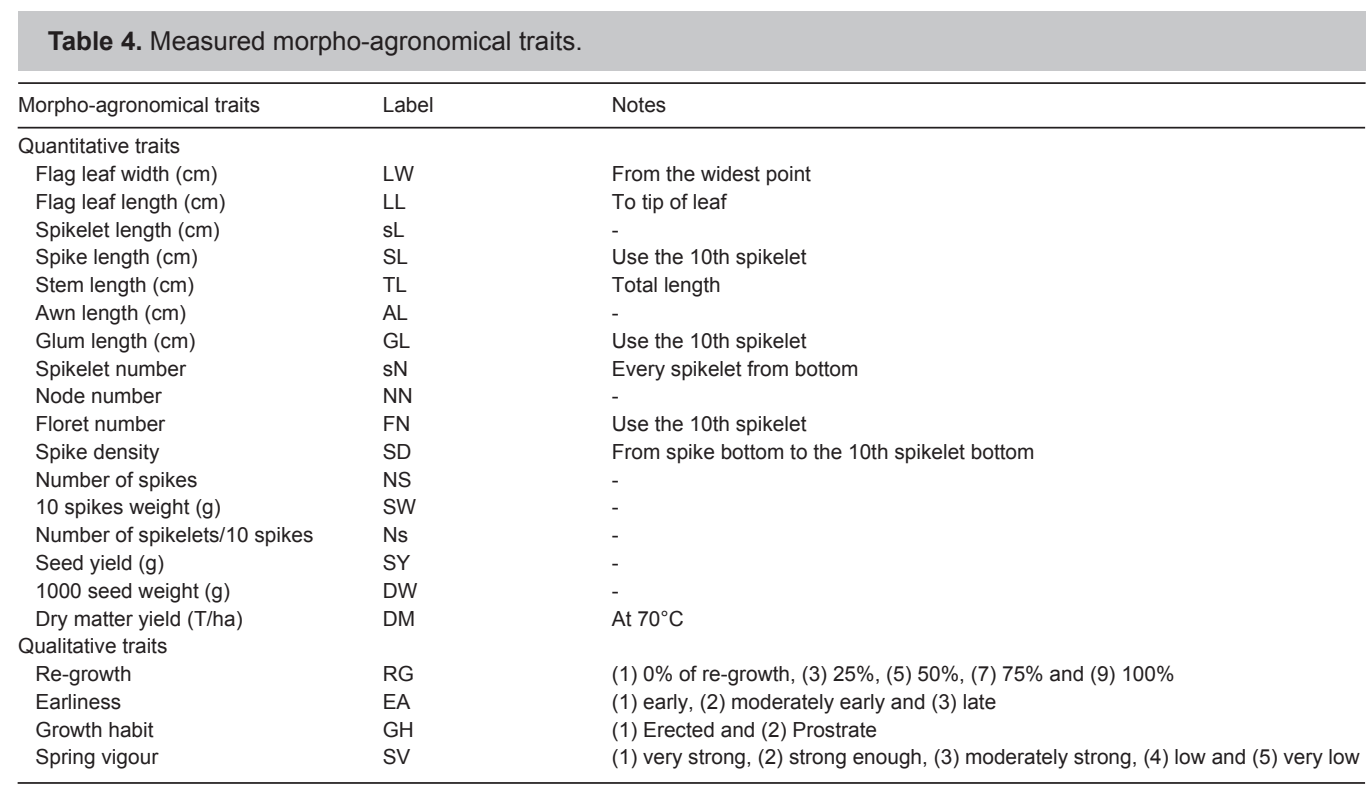

\section{Statistical analyses}

For each RAPD or ISSR primer used, the corresponding amplified products were recorded. Each marker was assumed by the presence (1) and/or absence (0) of the band. Data were compiled into a binary data matrix and submitted to diverse statistical analyses.

The polymorphism information content (PIC) values for ISSR and RAPD markers was determined using the web-line server (w3.georgikon.hu/pic/english/default.aspx) (Nagy et al., 2012) according to the formula PIC $=1$ - where fij is the frequency of the $i^{\text {th }}$ pattern revealed by the $j^{\text {th }}$ primer summed across all patterns revealed by the primer (Smith et al., 2000). Shannon index, genetic distances, cluster analysis, and the Mantel test were performed on the basis of the binary matrix data. UPGMA dendrograms were constructed from genetic similarity between pairwise genotypes according to Jaccard's coefficient (Jaccard, 1908).

The correspondence between each pair of matrix based on RAPD, ISSR, and morphoagronomical data was calculated with the Mantel test. All computations were performed using NTSYSpc (Version 2.11s) to identify genetic variation patterns among Tunisian perennial ryegrass (Rohlf, 2000). A Pearson correlation coefficient was established between the 21 analyzed morphoagronomical traits. These phenotypic traits were compiled into a binary matrix data and a total of 80 markers were obtained (Sneath and Sokal, 1973). The correlations between cophenetic matrix and genetic distances were assessed in order to evaluate the impact of these molecular markers on the observed morpho-agronomical traits. 


\section{RESULTS}

\section{RAPD markers}

A total of 90 reproducible patterns was detected, among which $88(97.8 \%)$ were polymorphic with a mean of 11.0 per primer (Table 2). In fact, results exhibited a maximum of 15 bands when using OPA-20 primer, and a minimum of 8 amplified fragments with OPA-14 primer.

The UPGMA dendrogram showed a monophyletic group corresponding to the local cultivated form (cA) (Figure 1a). Two sub-groups were also distinguishable. The first clustered the introduced cultivar (cT) with spontaneous accessions originated mainly from Jendouba locality (Ta, $\mathrm{Fr}, \mathrm{Hb}, \mathrm{Ef}$, et $\mathrm{Dr}$ ). All the remaining accessions are clustered in the second sub-group.
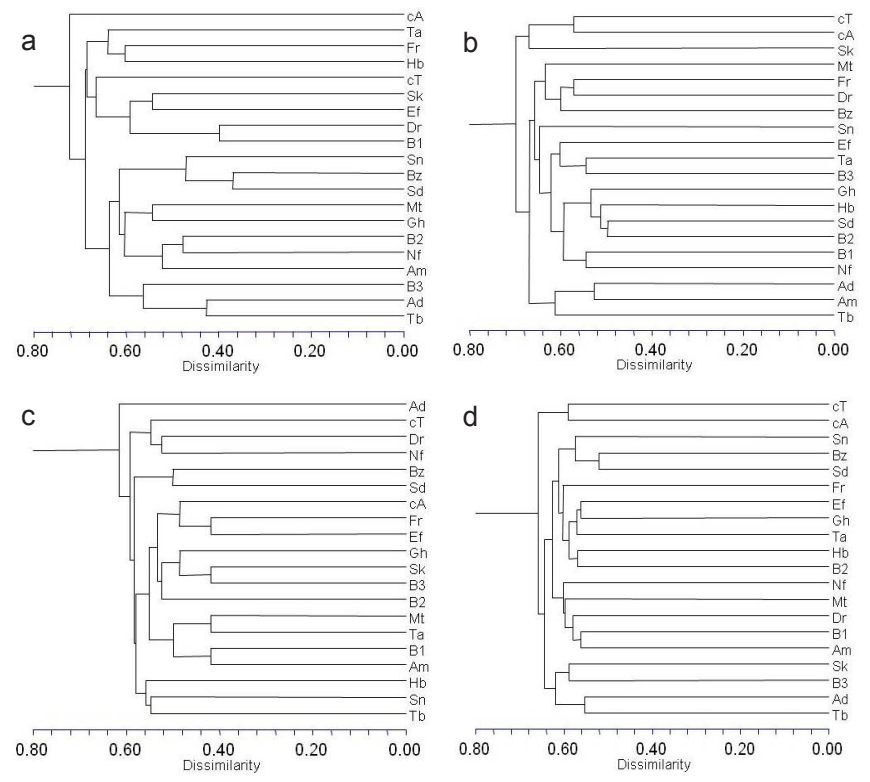

Figure 1. Dendrograms of 20 perennial ryegrass accessions showing the genetic dissimilarity based on RAPD (a), ISSR (b), morpho-agronomical traits (c) and combined (d) data sets using Jaccard's coefficient and UPGMA cluster analysis. Accession abbreviations as shown in table 1.

\section{ISSR markers}

The total number of polymorphic markers and the polymorphism percentage were 101 and $94.4 \%$, respectively. Among the eighteen bands, 8 were unambiguously generated with an average of 12.62 per primer (Table 3). The number of bands generated by anchored primers (67) was higher than that by simple ones (40). Di-nucleotidic repeated motifs seem to be more frequent than mono-nucleotidic microsatellites.

The cluster analysis divided Tunisian perennial ryegrass into two distinct groups (Figure 1b). The first group included cultivated forms (cA and cT) and the Skalba spontaneous accession (Sk) while the second cluster regrouped the remaining seventeen perennial ryegrass genotypes. The latter group is divided into two sub-clusters: the spontaneous accessions from Jendouba locality and the three spontaneous genotypes ( $\mathrm{Ad}, \mathrm{Am}$, and $\mathrm{Tb}$ ) originated from Beja locality. 


\section{Morpho-agronomical data}

The correlation between morpho-agronomical characters revealed significant coefficients (Table 5). High and positive correlations were scored between the ten spikes weight (SW) and seed yield (SY) (+0.846). These characters are agronomically important and contributed for seed production. Stem length (TL) was highly and positively correlated with spike length $(\mathrm{SL})$ and spikelet length $(\mathrm{sL})(+0.746$ and +0.708 , respectively). In addition, a high and positive correlation $(+0.717)$ was observed between plant architecture, node number (NN) and sL. Furthermore, statistical tests did not reveal any negative correlations. The majority of morpho-agronomical traits are related to forage performance and plant architectural morphology.

To analyze relationships between the 20 tested genotypes, a UPGMA algorithm dendrogram was constructed (Figure 1c). A monophyletic cluster regrouped the spontaneous Amdoun (Ad) accession characterized by the highest measured morpho-agronomical traits values especially the SL and the SY. The used morpho-agronomical traits clustered the remaining accessions into two sub-clusters. The Talbot cultivar (cT), Dar Hamra (Dr), and Nefza (Nf) accessions originated from Jendouba and Beja localities were regrouped in the first one, while, the local cultivar (cA) and several spontaneous accessions originated from the four studied localities in the second sub-cluster.

\section{Combination of RAPD, ISSR and morpho-agronomical data}

Characterization of the 20 studied perennial ryegrass accessions, using different approaches, revealed a large molecular pattern diversity depending on geographic origins (Table 6). In fact, rates of polymorphic bands were analogous using ISSR (37.54\%) and RAPD (32.71\%). Identical PIC values were obtained for both ISSR and RAPD markers $(0.374$ and 0.373 respectively). PIC values corresponding to morpho-agronomical markers were compared to those obtained completely from molecular data. In addition, it was seen that each molecular approach used separately was more efficient in detecting polymorphism than morpho-agronomical characters.

Combined data set based on 88 polymorphic RAPD bands, 101 ISSR polymorphic patterns, and 80 morpho-agronomical trait variants were exploited to estimate the genetic diversity structure. Mean genetic distance values calculated from morpho-agronomical traits (0.569), ISSRs (0.510), RAPDs (0.684), and combined data (0.525) proved that ISSR markers are more efficient to evaluate the genetic diversity (Table 6).

Range-wise genetic distances showed comparable values using RAPD and ISSR as markers; however, lower values were obtained using the morpho-agronomical traits. Similar results were obtained with estimation of Shannon diversity index, as exhibited by 0.573 for ISSR and 0.539 for RAPD data sets, while only 0.364 for morpho-agronomical data.

The null hypothesis of no correlation between different matrices was tested using the Mantel test with 10000 permutations (Table 7). ISSR markers showed significant correlation with RAPD approach $(r=0.173 ; p=0.016)$. The estimated value given for morpho-agronomical traits with ISSR data $(r=0.007 ; p=0.922)$ and RAPD matrix $(r=-0.077 ; p=0.283)$ were not significantly related.

Using all data sets for RAPD, ISSR and morpho-agronomical, an UPGMA dendrogram was constructed and showed in Figure 1d. Cultivars were separately grouped in the dendrogram. The cluster gathered spontaneous accessions and distinguished paired subgroups. The first included essentially Beja locality accessions. The second categorized the Bizerte locality accessions separately from Jendouba locality and the remaining Beja locality accessions. 


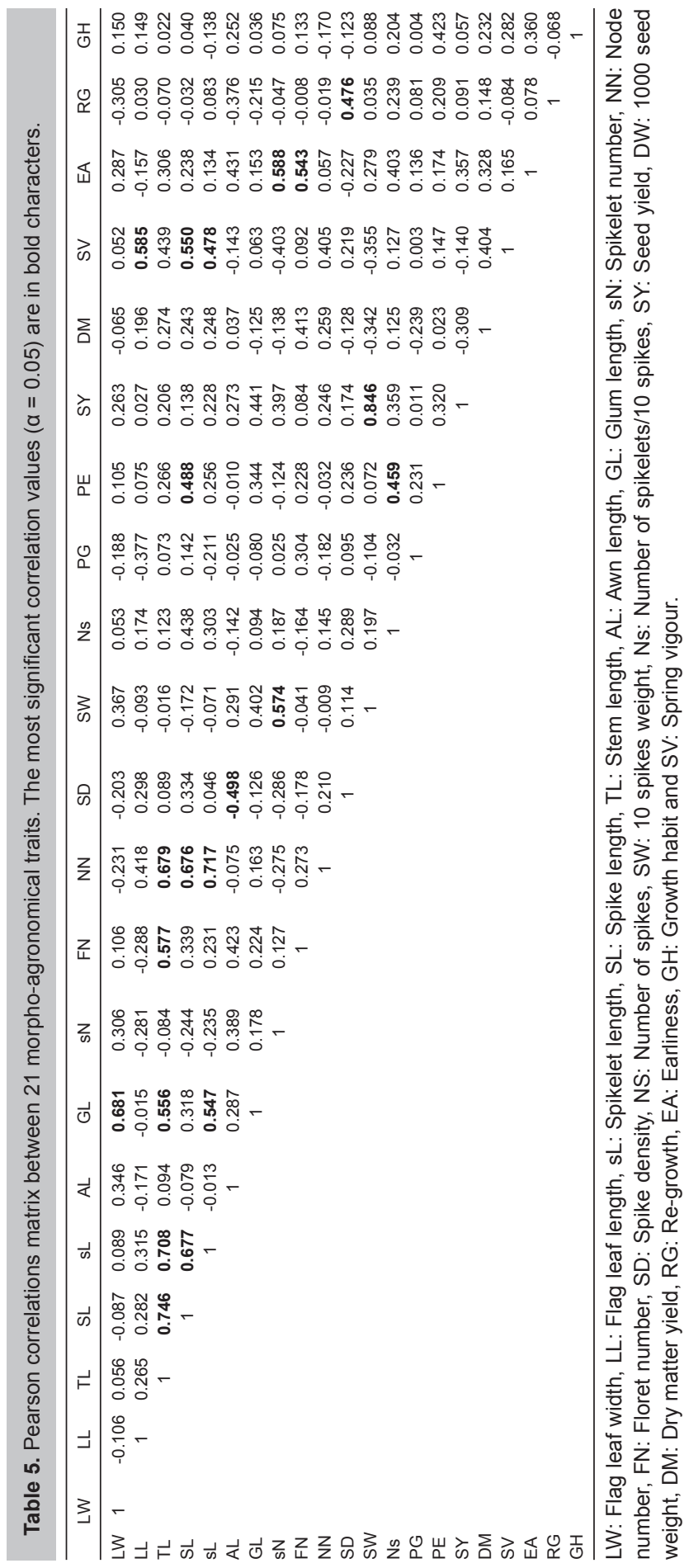


Table 6. Number of polymorphic markers, average and range of pairwise genetic distances, and Shannon index estimated among Tunisian perennial ryegrass accessions.

\begin{tabular}{|c|c|c|c|c|c|c|}
\hline \multirow[t]{2}{*}{ Marker system } & \multirow[t]{2}{*}{ No. of polymorphic markers } & \multirow[t]{2}{*}{$\%$ of polymorphism } & \multirow[t]{2}{*}{ PIC values } & \multicolumn{2}{|c|}{ Genetic distance } & \multirow[t]{2}{*}{ Shannon index } \\
\hline & & & & Average & Range & \\
\hline Morpho-agronomical & 80 & 29.85 & 0.3122 & 0.569 & $0.531-0.688$ & 0.364 \\
\hline RAPD & 88 & 32.71 & 0.3731 & 0.684 & $0.530-0.744$ & 0.539 \\
\hline ISSR & 101 & 37.54 & 0.3743 & 0.510 & $0.483-0.722$ & 0.573 \\
\hline Combined & 269 & 100 & 0.3683 & 0.525 & $0.337-0.685$ & 0.472 \\
\hline
\end{tabular}

Table 7. Mantel test values estimated for the three marker techniques.

\begin{tabular}{lll}
\hline & RAPDs & ISSRs \\
\hline ISSRs & $0.016(r=0.173)^{*}$ & \\
Morpho-agronomical traits & $0.283(r=-0.077)$ & $0.922(r=0.007)$ \\
\hline
\end{tabular}

*: Rejection of the null hypothesis of no correlation within a $5 \%$ confidence interval.

\section{DISCUSSION}

In order to characterize and promote the use of perennial ryegrass species, the genetic diversity and structure of Tunisian germplasm were studied. The conservation and utilisation of this species requires a thorough knowledge of its genetic background. Remarkably, local and introduced cultivars are heavily under-represented in ryegrass forage germplasm banks in spite of their great agronomic importance (Chakroun and Zouaghi, 2000). In addition, spontaneous germplasm were under-exploited in forage production yields (Chakroun et al., 1995). DNA fingerprinting is the routine method used to explore the degree of genetic diversity in a set of germplasm or cultivars. Recently, molecular reports described characterization of ryegrass from Tunisian resources (Ghariani et al., 2003b; Elazreg et al., 2011).

In the current study, we used RAPD, ISSR, and morpho-agronomical fingerprinting data separately as well as together to improve the content and genetic variability level of Tunisian perennial ryegrass. The results demonstrated that each separately used molecular approach was more efficient in detecting polymorphism than morpho-agronomical characters.

The important polymorphism detected by the use of a single tool or the combination of three tools (as mentioned above) demonstrated a large genetic diversity in Tunisian ryegrass germplasm.

Cluster analysis was carried out on three sets of markers profiling data based on RAPD, ISSR, morpho-agronomical fingerprinting, and on the combination of all data sets. Similar findings were reported in previous investigation (Geleta et al., 2006). The genotype branching was dependent on geographic origin accession.

Clustering based on molecular data analysis distinguished local and introduced cultivars displaying various genotypes and/or diverse selection program. However, this consideration is in agreement with the unknown origin of both cultivars suggesting a complex domestication process in these crops (Ghariani et al., 2003b). Based on morpho-agronomical data, cultivated forms constituted a unique cluster demonstrating the impact of domestication in local eco-edaphic conditions.

The branching of spontaneous accessions is dependent on geographic localities, for example, in Jendouba locality, as found by the use of molecular markers, and in Beja locality by combined analysis. It is important to note that significant and positive correlation values were obtained for important agronomic characters as $\mathrm{SL}$ and $\mathrm{SY}$ which are implicated in agronomic 
forage production potentialities. Similar results have been already reported in several works (Chakroun et al., 1995; Charmet et al., 1997).

It was assumed that Talbot introduced cultivar (cT) shares morpho-agronomical similarities with Dar Hamra (Dr) and Nefza (Nf) spontaneous accessions, suggesting an adaptation to Tunisian abiotic and biotic conditions as a result of domestication in Tunisian environment. It may be assumed that identified spontaneous populations would provide alternative phylogenetic resources suitable for cultivar selection programs to improve northern Tunisian grasslands. Beja and Jendouba spontaneous accessions showed large similarities with cultivated forms, suggesting genetic exchanges and gene flow justified by preferentially allogamous mating system (Elazreg et al., 2011). The combined analysis helped us to suppose that Beja and Jendouba should be the more suitable accession localities that could be exploited in perennial ryegrass improvement programs.

\section{Conflicts of interest}

The authors declare no conflict of interest.

\section{ACKNOWLEDGMENTS}

We gratefully acknowledge the financial support from the Ministère de l'Enseignement Supérieur, de la Recherche Scientifique et des Technologies de I'Information et de la communication (Tunisia).

\section{REFERENCES}

Bert PF, Charmet G, Sourdille P, Hayward MD, et al. (1999). A high-density molecular map for ryegrass (Lolium perenne) using AFLP markers. Theor. Appl. Genet. 99: 445-452.

Chakroun M and Zouaghi M (2000). Conservation and evaluation of forage and pasture genetic resources of northern Tunisia. Plant Genet. Resour. Newsl. 123: 46-51.

Chakroun M, Mezni MY, Cunningham P and Graves W (1995). Genetic resources collection of perennial pasture grasses in Tunisia. Cahiers Options Méditerranéennes 12: 49-51.

Charmet G, Ravel C and Balfourier F (1997). Phylogenetic analysis in the Festuca-Lolium complex using molecular markers and ITS rDNA. Theor. Appl. Genet. 94: 1038-1046.

Cunningham PJ, Graves WL, Chakroun M, Mezni MY, et al. (1997). Novel perennial germplasm from North Africa and Sardinia. Aust. Plant Int. Rev. 27: 13-46.

Dellaporta SL, Wood J and Hicks JB (1983). A plant DNA minipreparation: Version II. Plant Mol. Biol. Rep. $1: 19-21$.

Elazreg H, Ghariani S, Chtourou-Ghorbel N, Chakroun M, et al. (2011). SSRs transferability and genetic diversity of Tunisian Festuca arundinacea and Lolium perenne. Biochem. Syst. Ecol. 39: 79-87.

Fang DQ and Roose ML (1997). Identification of closely related citrus cultivars with inter-simple sequence repeat markers. Theor. Appl. Genet. 95: 408-417.

Geleta N, Labuschagne MT and Viljoen CD (2006). Genetic diversity analysis in sorghum germplasm as estimated by AFLP, SSR and morpho-agronomical markers. Biodiversity and Conservation. 15: 3251-3265.

Ghariani S, Chakroun M, Trifi-Farah N, Marghali S, et al. (2003a). Multivariate analysis for agronomic evaluation of Tunisian perennial ryegrass germplasm collection. Czech J. Genetics and Plant Breed. 39 (Special issue): 201-204.

Ghariani S, Trifi-Farah N, Chakroun M, Marghali S, et al. (2003b). Genetic diversity in Tunisian perennial ryegrass revealed by ISSR markers. Genetic Resour. Crop Evol. 50: 809-815.

Ghariani S, Trifi-Farah N, Chakroun M, Marghali S, et al. (2003c). Morphological characterization of Tunisian perennial ryegrass germplasm. J. Genet. Breed. 57: 185-190.

Gilbert JE, Lewis RV, Wilkinson MJ and Caligari PDS (1999). Developing an appropriate strategy to assess genetic variability in plant germplasm collections. Theor. Appl. Genet. 98: 1125-1131.

Gupta M, Chyi YS, Romero-Severson J and Owen JL (1994). Amplification of DNA markers from evolutionarily diverse genomes using single primers of simple-sequence repeats. Theor. Appl. Genet. 89: 998-1006. 
Hayward MD, McAdam NJ, Jones JG, Evans C, et al. (1994). Genetic markers and the selection of quantitative traits in forage grasses. Euphytica. 77: 269-275.

Hayward MD, Forster JW, Jones JG, Dolstra O, et al. (1998). Genetic analysis of Lolium. I. Identification of linkage groups and the establishment of a genetic map. Plant Breed. 117: 451-455.

Jaccard P (1908). Nouvelles recherches sur la distribution florale. Bull. Soc. Vaud. Sci. Nat. 44: 223-270.

Jones ES, Dupal MP, Kölliker R, Drayton MC, et al. (2001). Development and characterisation of simple sequence repeat (SSR) markers for perennial ryegrass (Lolium perenne L.). Theor. Appl. Genet. 102: 405-415.

Jones S, Dupal P, Dumsday L, Hughes J, et al. (2002). An SSR-based genetic linkage map for perennial ryegrass (Lolium perenne L.). Theor. Appl. Genet. 105: 577-584.

Krichen L, Bourguiba H, Audergon J-M and Trifi-Farah N (2010). Comparative analysis of genetic diversity in Tunisian apricot germplasm using AFLP and SSR markers. Sci. Hortic. 127: 54-63.

Linos A, Nikoloudakis N, Katsiotis A and Hagidimitriou M (2014). Genetic structure of the Greek olive germplasm revealed by RAPD, ISSR and SSR markers. Sci. Hortic. 175: 33-43.

Muthusamy S, Kanagarajan S and Ponnusamy S (2008). Efficiency of RAPD and ISSR markers system in accessing genetic variation of rice bean (Vigna umbellata) landraces. Electron. J. Biotechnol. 11: 32-41.

Nagy S, Poczai P, Cernák I, Gorji AM, et al. (2012). PICcalc: an online program to calculate polymorphic information content for molecular genetic studies. Biochem. Genet. 50: 670-672.

Rohlf FJ (2000). NTSYS-PC, numerical taxonomy system for the PC ExeterSoftware, Version 2.1. Applied Biostatistics Inc Setauket.

Russell J, Ellis R, Thomas WB, Waugh R, et al. (2000). A retrospective analysis of spring barley germplasm development from 'foundation genotypes' to currently successful cultivars. Mol. Breed. 6: 553-568.

Sambrook J, Fritsch EF and Maniatis T (1989). Molecular Cloning: A Laboratory Manual. Second Edition. Cold Spring Harbor Laboratory Press, Cold Spring Harbor.

Smith JSC, Kresovich S, Hopkins MS, Mitchell SE, et al. (2000). Genetic Diversity among Elite Sorghum Inbred Lines Assessed with Simple Sequence Repeats. Crop Sci. 40: 226-232.

Sneath PHA and Sokal RR (1973). Numerical taxonomy. The principles and practice of numerical classification.

Trifi M, Rhouma A and Marrakchi M (2000). Phylogenetic relationships in Tunisian date-palm (Phoenix dactylifera L.) germplasm collection using DNA amplification fingerprinting. Agronomie, EDP Sci. 20: 665-671.

Yao H, Zhao Y, Chen DF, Chen JK, et al. (2008). ISSR primer screening and preliminary evaluation of genetic diversity in wild populations of Glycyrrhiza uralensis. Biol. Plant. 52: 117-120. 